\title{
Maternal mortality-a three-year retrospective study in a rural medical college of India
}

\author{
Jayasree Hansda ${ }^{1}$, Debobroto Roy ${ }^{1 *}$, Krishnapada Das¹, Manojit Sarkar², \\ Rumpa Das ${ }^{1}$, Arpita Pramanik ${ }^{1}$
}

\begin{abstract}
${ }^{1}$ Department of Obstetrics and Gynecology, Burdwan Medical College and Hospital, Burdwan, West Bengal, India
${ }^{2}$ Department of Surgery, Nil Ratan Sircar Medical College and Hospital, Kolkata, West Bengal, India
\end{abstract}

Received: 06 March 2021

Accepted: 21 June 2021

*Correspondence:

Dr. Debobroto Roy,

E-mail: msmanojit94@gmail.com

Copyright: ( $)$ the author(s), publisher and licensee Medip Academy. This is an open-access article distributed under the terms of the Creative Commons Attribution Non-Commercial License, which permits unrestricted non-commercial use, distribution, and reproduction in any medium, provided the original work is properly cited.

\begin{abstract}
Background: Maternal mortality is a tragic event as family revolves around a mother. The deadly obstetrical triad of hemorrhage, preeclampsia and infection has accounted for a third of all deaths. This study was conducted to assess maternal mortality ratio, demographic profile and causes of maternal death.

Methods: This retrospective longitudinal study was conducted in the department of obstetrics and gynecology for a period of three years from $1^{\text {st }}$ January 2018-31 $1^{\text {st }}$ December, 2020. Total no of death during this period was 134.Records of deaths and demographic profiles were retrieved from the medical record library of aforesaid hospital.

Results: There were 134 maternal deaths amongst 56815 live births with MMR 235.85. The majority of deaths were in 20-29 year of age group and most of the deaths seen in multigravida. The $91.79 \%$ death was observed within the 24 hours and after 72 hours. Eclampsia, preeclampsia and hemorrhage were leading cause of maternal death seen in the study.

Conclusions: Maternal mortality is higher than national MMR. Majority of maternal death were preventable by proper antenatal care, early detection of high-risk pregnancies and their timely referral to tertiary care centre.
\end{abstract}

Keywords: Eclampsia, Hemorrhage, Maternal mortality, Preeclampsia

\section{INTRODUCTION}

Maternal death is a tragic condition as it occurs during or after natural process. As per world health organization, maternal death is the death of the women while pregnant or within 42 days of termination of pregnancy irrespective of the duration and site of pregnancy from any cause related to or aggravated by the pregnancy or its management, but not from accidental or incidental causes. One of the key indicators of maternal mortality is maternal mortality ratio (MMR) which is defined as the number of maternal deaths during a given time period per 100,000 live births during the same time period. The index of the quality of health care delivery system of a country as a whole or in part is reflected by its MMR.
Maternal mortality is unacceptably high. About 295000 women died during and following pregnancy and child birth in 2017 globally. The vast majority of death (94\%) occurred in low resource setting and most could have been prevented. ${ }^{1}$ Sub-Saharan and Southern Asia accounted for approximately $86 \%(254,000)$, of estimated global maternal death in 2017.

Africa alone accounted for roughly two thirds (196000) of maternal deaths while Southern Asia accounted for nearly $1 / 5^{\text {th }}(58,000)$. WHO commends India for its ground breaking progress in recent years in reducing the MMR by $77 \%$, from 550 per 100,000 live births to 130 per 100,000 live births in 2016. India's present MMR is below the millennium development goal (MDG) target and puts the 
country on track to achieve the sustainable development goal (SDG) of MMR below 70 by $2030 .^{2}$ As per national health policy (NHP) 2017, the target for MMR is 100 per 100,000 live births by 2020 .

A special bulletin by sample registration system office of the registrar general, India provides the level of maternal mortality for the period 2016-2018. It is heartening that the MMR of India has declined to 113 in 2016-2018 from 122 in 2015-2017 and 130 in 2014-2016. ${ }^{3}$

Women die as a result of complications during and following pregnancy and child birth. Most of these complications developed during pregnancy and most are preventable or treatable. Other complications may exist before pregnancy but are worsened during pregnancy, especially which are not managed as part of the woman's care. The major complications that account for nearly $75 \%$ of all maternal deaths are severe bleeding (mostly bleeding after child birth), infection (usually after child birth), high blood pressure during pregnancy (Pre-eclampsia and eclampsia), complications from delivery or unsafe abortion. ${ }^{4}$ The major causes of maternal mortality are preventable through regular antenatal checkup, proper diagnosis and management of labor complications.

Burdwan medical college and hospital is a rural medical college and large no of pregnant mother with high risk factors, mother with PROM, obstructed labor and prolonged labor and mother with abnormal puerperium are referred from BPHC, SD and state general hospital in bad shape which died after admission. We conducted this study to find out MMR, demographic profile and causes of maternal death.

\section{METHODS}

This study was carried out in obstetrics and gynecology department of Burdwan medical college-A rural tertiary care centre at Burdwan, West Bengal in India. The study was conducted by reviewing the records of maternal deaths over a period of three years from $1^{\text {st }}$ January, 2018-31 $1^{\text {st }}$ December, 2020.

This was a longitudinal study. Every maternal death was carefully reviewed with special emphasis on age, parity, socioeconomic status, time of death, admission-death interval and causes of death.

\section{Exclusion criteria}

All doubtful cases, all accidental cases, maternal deaths occurring beyond 42 days postpartum and incidental causes were excluded from the study.

\section{Statistical analysis}

Data was analyzed by using SPSS version 11 . Frequency and percentage were calculated for qualitative variables e.g., age, parity, incidence and socio-economic status.

\section{RESULTS}

During the study period, there were 134 maternal deaths out of 56815 live births giving MMR of 235.85 in our institution. Majority of deaths occurred in the age group of 20-29 years (59.7\%) and were multigravida (65.67\%), while $78.36 \%$ of patients were referred from other hospital. It is observed that most of the death occurred in post-partum period $(91.79 \%)$ and majority of maternal death occurred before 24 hours and after 72 hours of admission (38.8\% in each group).

Analysis of the causes of death revealed that eclampsia is the leading cause of death. 36 deaths (26.86\%), out of 134 deaths were due to eclampsia; 29 deaths (21.64\%) were due to obstetric hemorrhage. Obstetric hemorrhage includes atony, following caesarean section, placenta previa. Sepsis related deaths were 18 (13.43\%) and pregnancy induced hypertension related death were 15 $(12.68 \%)$. Anemia, heart disease and pulmonary embolism each account for 7 deaths (5.22\%). 5 deaths (3.73\%) were caused by hepatic coma following jaundice. Renal failure is responsible for $2.98 \%$ of death and suspected amniotic fluid embolism causes $2.98 \%$ of death. Diabetic keto acidosis causes 1 death like that of ARDS.

Table 1: Year wise distribution of maternal death and live birth.

\begin{tabular}{|llll|}
\hline Years & $\begin{array}{l}\text { Maternal } \\
\text { death }\end{array}$ & Live birth & MMR \\
\hline $\mathbf{2 0 1 8}$ & 54 & 18892 & 285.84 \\
\hline $\mathbf{2 0 1 9}$ & 34 & 20488 & 165.95 \\
\hline $\mathbf{2 0 2 0}$ & 46 & 17435 & 263.84 \\
\hline Total & 134 & 56815 & 235.85 \\
\hline
\end{tabular}

Table 2: Maternal deaths and its characteristics.

\begin{tabular}{|c|c|c|c|}
\hline Characteristics & Groups & $\begin{array}{l}\text { Maternal } \\
\text { deaths }\end{array}$ & $\begin{array}{l}\text { Percent } \\
(\%)\end{array}$ \\
\hline \multirow{4}{*}{ Age (years) } & $15-19$ & 37 & 27.61 \\
\hline & $20-29$ & 80 & 59.70 \\
\hline & $30-39$ & 17 & 12.68 \\
\hline & $>40$ & 0 & 0 \\
\hline \multirow{2}{*}{ Parity } & Primi & 46 & 34.32 \\
\hline & Multi & 88 & 65.67 \\
\hline \multirow[b]{2}{*}{ Antenatal care } & Referral & 105 & 78.36 \\
\hline & $\begin{array}{l}\text { Non } \\
\text { referral }\end{array}$ & 29 & 21.64 \\
\hline \multirow{2}{*}{$\begin{array}{l}\text { Socio } \\
\text { economic } \\
\text { status }\end{array}$} & Low & 112 & 83.58 \\
\hline & Middle & 22 & 16.42 \\
\hline \multirow{3}{*}{ Time of death } & Antepartum & 11 & 8.20 \\
\hline & Intrapartum & 0 & 0 \\
\hline & Postpartum & 123 & 91.79 \\
\hline \multirow{4}{*}{$\begin{array}{l}\text { Admission } \\
\text { death interval } \\
\text { (hours) }\end{array}$} & $<24$ & 52 & 38.80 \\
\hline & $24-48$ & 23 & 17.16 \\
\hline & $48-72$ & 7 & 5.22 \\
\hline & $>72$ & 52 & 38.80 \\
\hline
\end{tabular}


Table 3: Causes of maternal death $(n=134)$.

\begin{tabular}{|lll|}
\hline Causes & No. of death & Percentage (\%) \\
\hline Direct cause & & \\
\hline Eclampsia & 36 & 26.86 \\
\hline Hemorrhage & 29 & 21.64 \\
\hline Septicemia & 18 & 13.43 \\
\hline Preeclampsia & 15 & 12.68 \\
\hline $\begin{array}{l}\text { Pulmonary } \\
\text { embolism }\end{array}$ & 7 & 5.22 \\
\hline $\begin{array}{l}\text { Amniotic fluid } \\
\text { embolism }\end{array}$ & 4 & 2.98 \\
\hline Indirect cause & & \\
\hline Anemia & 7 & 5.22 \\
\hline Heart disease & 7 & 5.22 \\
\hline Jaundice & 5 & 3.73 \\
\hline Renal failure & 4 & 2.98 \\
\hline Diabetes (DKA) & 1 & 0.74 \\
\hline ARDS & 1 & 0.74 \\
\hline
\end{tabular}

\section{DISCUSSION}

The MMR in our present study is 235.85 per 100000 live births, which is higher than the state and national averages. Most of the women were referred from other hospitals resulting in delayed intervention and many were in poor general condition at the time of admission. $\mathrm{BMCH}$, being a tertiary care centre and a teaching institution, get complicated cases from rural areas. Admission of moribund cases referred $(78.36 \%)$ from periphery have inflated this mortality ratio, like other teaching institution of India. ${ }^{5,6}$ Most deaths were observed in the 20-29 years age group in present study which is similar to other study. ${ }^{7}$ Maternal mortality is more in multigravida mother $(65.67 \%)$ in our study and this shows that too many pregnancies and short inter-conception period adversely affects the health and social status of the women. Other studies by Sethi et al and Thomas et al also showed that multigravida contributing $55 \%$ and $50.8 \%$ of maternal deaths respectively. ${ }^{8,9}$ Most patients were from low socioeconomic status $(83.58 \%)$ and this is consistent with other findings..$^{10,11}$

Post-partum deaths accounted for about $91.79 \%$ of maternal mortality, and this is similar to other studies. In this study maximum deaths occurred within 24 hours and after 72 hours of admission, $38.80 \%$ in each group. Nair et al in their study found $44.90 \%$ maternal deaths occurred within $24 \mathrm{~h}$ and $42.60 \%$ within 1-6 days of hospital admission. ${ }^{12}$ Priya et al in their study also observed maximum deaths $(54.63 \%)$ within 24 hours of hospital admission. ${ }^{13}$ It becomes apparent that many of the deaths that occurred could have been avoided if they were transferred earlier further highlighting the need for adequate and quick transport facilities.

Eclampsia, as seen in our study found to be the leading cause of death $(26.68 \%)$ followed by hemorrhage $(21.64 \%)$ and septicemia account $13.43 \%$. Our findings were consistent with studies by Bhaskar et al, Onakewhor et al, Jadhav et al. ${ }^{10.11,14}$ Preeclampsia account for $12.68 \%$ of death in this study. Hypertensive disorder of pregnancy causing maximum number death $(39.36 \%)$ in this study. Even today large number of maternal deaths were due to classic triad of haemorrhage, hypertensive disorders and sepsis.

Indirect cause of death account for $18.63 \%$ of total maternal death in this study. Anemia, heart disease and jaundice responsible for $5.22 \%, 5.22 \%$ and $3.73 \%$ of maternal death respectively. These are similar to other studies. ${ }^{10,11}$

\section{Limitations}

As Burdwan medical college is a rural one, large no of cases was admitted in poor shape due to late referral and poor transport system and hence admission-death interval is short in big percentage of cases $(38.80 \%)$ and in these cases proper causes evaluation and management are difficult.

\section{CONCLUSION}

The MMR in our study is higher like other tertiary care centre. A number of sociodemographic factors affect maternal mortality. It was observed that poor, illiterate women with poor knowledge regarding spacing of birth, inadequate $\mathrm{ANC}$, coming from remote rural areas are more vulnerable to morbidity and mortality. Eclampsiapreeclampsia, hemorrhage and septicemia were major the direct causes of maternal death. All these are preventable causes of maternal mortality provided the treatment is instituted in time. Maternal deaths can be prevented by improving the health care facilities in rural areas by ensuring round the clock availability of certain basic drugs like injection magnesium sulfate, tablet misoprostol as most maternal deaths in rural areas are still due to eclampsia and postpartum hemorrhage. Early detection of high-risk pregnancies and referring them to a tertiary centre at the earliest can reduce the complications of highrisk pregnancies. Early correction of anemia and health education on importance of IFA tablets will reduce death due to anemia. Lastly most deaths could have been avoided with the help of good antenatal, intra-natal and postnatal care, early referral, quick, efficient and well-equipped transport facilities, availability of adequate blood and blood components, and promoting overall safe motherhood.

\section{Funding: No funding sources \\ Conflict of interest: None declared \\ Ethical approval: The study was approved by the Institutional Ethics Committee}

\section{REFERENCES}

1. Trends in maternal mortality: 2000 to 2017: estimates by WHO, UNICEF, UNFPA, World Bank Group and 
the United Nations Population Division. Geneva: World Health Organization. 2019. Available at: https://www.unfpa.org/featured-publication/trendsmaternal-mortality-2000-2017.

2. WHO. Regional Office for South East Asia. India. 2018.

https://www.who.int/southeastasia/about/governance /regional-director.

3. Special bulletin on maternal mortality in India 201618 sample registration system office of the registrar general, India vital statistics division, New Delhi. 2020.

4. Say L, Chou D, Gemmill A, Tunçalp Ö, Moller AB, Daniels JD et al. Global Causes of Maternal Death: A WHO Systematic Analysis. Lancet Global Health. 2014;2(6):e323-33.

5. Rushali RL, Uday WN, Rajat L. Maternal Mortality in a Tertiary Care Hospital of Central India: A 5 years review. J Med Sci Clin Res. 2017;05(12):31820-4.

6. Purandare N, Singh A, Upahdya S. Maternal mortality at a referral centre: a five-year study. J Obstet Gynaecol India. 2007;57(3):248-50.

7. Ashok V, Santosh M, Anupa S. A study on maternal mortality. J Obstet Gynecol. 2008;58:226-9.
8. Sethi PS. Maternal mortality in a tertiary care centre in North India: a retrospective study Int J Reprod Contracept Obstet Gynecol. 2017;6(12):5559-62.

9. Thomas B, Mhaskar A. Review of maternal mortality at tertiary care hospital of India over ten years, Int $\mathbf{J}$ Gynecol Obstet India. 2006;9(5):19-21.

10. Onakewhor JU, Gharoro EP. Changing trends in maternal mortality in a developing country. Niger $\mathbf{J}$ Clin Pract. 2008;11:111-20.

11. Jadhav AJ, Rote PG. Maternal mortality-changing trends. J Obstet Gynaecol India. 2007;57:398-400.

12. Nair A, Doibale MK, Gujrathi VV, Inamdar IF, Shingare AD, Rajput PS. Study of maternal mortality in a tertiary care hospital in a district of Maharashtra. Int J Med Sci Public Health. 2016;5(09).

13. Priya N, Verma A, Verma S. Maternal mortality: ten years retrospective study. JK Sci. 2010;12(3):134-6.

14. Murthy BK, Murthy MB, Prabhu PM. Maternal Mortality in a Tertiary Care Hospital: A 10-year Review. Int J Prev Med. 2013;4(1):105-9.

Cite this article as: Hansda J, Roy D, Das K, Sarkar M, Das R, Pramanik A. Maternal mortality-a threeyear retrospective study in a rural medical college of India. Int J Reprod Contracept Obstet Gynecol 2021;10:3019-22. 